\title{
Problemática del mercado ecoturístico en la Reserva de la Biosfera Sierra La Laguna: El caso de San Dionisio, Baja California Sur
}

DOI: 10.22403/UQROOMX/TYP10/03

Lucía Fasio Reyna Ibáñez Universidad Autónoma de Baja California Sur Departamento de Economía en UABCS

\section{RESUMEN}

San Dionisio, Baja California Sur (B.C.S.), localidad ubicada dentro de la Reserva de la Biosfera Sierra La Laguna (Rebisla), comprende un ecosistema de interés para la conservación. En los últimos años esta comunidad ha reflejado una participación activa en el ámbito turístico a pesar de contar con poca población y baja promoción de su oferta turística. El objetivo de este artículo es presentar un diagnóstico y caracterización que permita determinar las fortalezas, oportunidades, debilidades y amenazas del mercado ecoturístico de San Dionisio. Los resultados apuntan a que la problemática en San Dionisio se debe a la carencia de planeación del desarrollo turístico, lo que repercute en una escasa diversificación de sus servicios y la falta de capacitación para mejorar la calidad en el servicio. Los aspectos mencionados son elementos que pueden ser recuperados por los tomadores de decisiones para replantear el desarrollo del turismo en la localidad, de manera tal que se generen mayores beneficios sin poner en riesgo la sustentabilidad local.

\begin{tabular}{r|r} 
Palabras & Biosfera, ecoturístico, mercado, reserva, turístico
\end{tabular}

Recibido el 2 de octubre de 2010

Aprobado el 24 de noviembre de 2010

Correos electrónicos: fasio_14@hotmail.com•ribanez@uabcs.mx 


\section{Introducción}

Los modelos turísticos tradicionales, basados en actividades de turismo masivo, se caracterizan por el desplazamiento sincrónico de una gran cantidad de personas, en épocas muy marcadas del año, con la finalidad de realizar actividades vinculadas con descanso, deporte, diversión, cultura, salud y religión. Esta tendencia puede observarse en algunos destinos turísticos de sol y playa, donde las personas buscan básicamente entretenimiento y diversión, se interesan por comprar paquetes turísticos baratos que incluyen transportación aérea y hospedaje y donde los atributos del lugar no importan tanto como el precio (Bringas y Ojeda, 2000). En general, ese tipo de destinos tienden a generar desarrollos de tipo exógeno, sustentados en la gran empresa y la inversión extranjera, lo que redunda en el surgimiento de economías de enclave turístico, que no son otra cosa que un complejo hotelero o gran centro turístico ajeno a la comunidad receptora, estos centros turísticos están deliberadamente diseñados para ser ajenos al entorno social, se asemejan mucho unos a otros $y$ muy poco a sus alrededores, dependen en gran medida de inversión foránea y se caracterizan por la existencia de una escasa interacción entre la comunidad receptora y el turista (Manning, 1996).

En contraparte, los modelos de planeación participativa promueven la realización de actividades sustentables que consideran el papel activo y dinámico de la sociedad civil, a través de las comunidades locales o de asociaciones representativas de sus intereses. Es tal la importancia que han adquirido esos modelos que se busca su implementación en lugares que poseen alta riqueza natural y que cuentan con potencial para realizar actividades que involucran una constante interacción entre el hombre y la naturaleza, lo que en términos socioambientales los hace más vulnerables (lbáñez, 20 I la).

En México, se han formulado estrategias nacionales para fomentar ese tipo de actividades en áreas del país propicias para ello. Algunos ejemplos son la Estrategia Nacional para un Desarrollo Sustentable del Turismo y la Recreación en las Áreas Protegidas de México (Conanp, 20 I I) y el Plan Nacional de Turismo en ANP (Conanp, 2007), donde se impulsa la realización de activida-des vinculadas con el turismo alternativo,' ya que se busca complementar las fuentes de ingresos

'Es una modalidad turística que tiene por objetivo ser consecuentes con los valores naturales, sociales y comunitarios (Sectur, 2004), que permita tanto a los anfitriones como a los turistas disfrutar de una interacción positiva (Wearing y Neil, 1999: 24).

TEORÍA Y PRAXIS

10 (201 I: 49-75) 
y se intenta generar opciones de desarrollo respaldadas en el aprovechamiento de las potencialidades de los habitantes de las localidades, a fin de que éstos sean capaces de liderar sus propios procesos de desarrollo (lbáñez, 2007), pero en el entendido de que ese desarrollo debe basarse en los principios de equidad, eficiencia y uso sustentable del ambiente, dado que ello permitirá alcanzar un desarrollo que satisfaga las necesidades de la generación presente, sin comprometer la capacidad de las generaciones futuras para satisfacer sus propias necesidades (СB, 1987). No obstante, la implementación de dichas actividades debe apoyarse en un proceso de planeación detallada donde se consideren las potencialidades con las que se cuenta, desde el punto de vista económico, social, cultural, ambiental, organizacional, legal, etc. Desafortunadamente muchos desarrollos y modelos turísticos están condenados al fracaso al no tener en cuenta serias barreras como la falta de capacitación, infraestructura, demanda, aceptación comunitaria y bajo apoyo por parte del sector gubernamental (lbáñez, 20l lb).

Con base en lo anterior, este artículo tiene como finalidad estudiar las problemáticas y características del mercado ecoturístico dentro de la Rebisla, en concreto en el poblado San Dionisio, que comprende una serie de rancherías, con un ecosistema de interés para la conservación y recreación. Recientemente, instituciones como la Conanp, la Secretaría del Medio Ambiente y Recursos Naturales (Semarnat, 2003), y la Secretaría de Turismo (Sectur, 2007) han iniciado un estrecho trabajo con los habitantes de esa localidad, a fin de generar una participación activa en el ámbito turístico, a pesar del bajo nivel de población, y la escasa planeación, promoción y capacitación turística. Tales instituciones han fomentando y financiado algunos proyectos vinculados con el ecoturismo, actividad acorde con el uso sustentable de la zona. Por ello, este estudio busca también establecer un diagnóstico de sus debilidades, amenazas, fortalezas y oportunidades, con la finalidad de aportar elementos para que los tomadores de decisiones puedan implementar medidas que contribuyan a una gestión más exitosa de dicha actividad. 


\section{Metodología}

Dado que este estudio corresponde a una investigación de carácter exploratorio y descriptivo, la metodología utilizada se basó en la recopilación de información obtenida a través de fuentes primarias, secundarias y métodos específicos como el análisis de fortalezas, oportunidades debilidades, amenazas (FODA). Los cuales se describen a continuación:

Fuentes primarias. Para obtener la información necesaria para analizar e identificar la infraestructura y los servicios del área de estudio, se realizó una visita de familiarización con los lugareños, lo que facilitó el diseño de métodos e instrumentos de recopilación de información. Posteriormente, se efectuaron cinco visitas de campo en las que se recopilaron datos para caracterizar el área, tomando en cuenta elementos físicos y sociales.

Cabe señalar que, con la finalidad de conocer aspectos como forma de vida, nivel educativo, características de las viviendas y percepción local del desarrollo del turismo, se aplicaron encuestas en 13 de los 14 ranchos que conforman la zona de estudio. De manera paralela, se realizaron entrevistas con agentes clave: prestadores de servicios turísticos de la comunidad, encargados de la administración del área, integrantes de cuerpos académicos de la Universidad Autónoma de Baja California Sur (UABCS), etc.Además, se utilizaron instrumentos metodológicos complementarios como fichas de observación, formatos de entrevista, registros fotográficos y grabaciones de voz. También se aplicaron aleatoriamente 59 encuestas a turistas (el número de encuestados corresponde a una muestra del $10 \%$ del total de turistas que cada año visita la zona) y se efectuó observación directa mediante labores de servicio social durante más de seis meses, periodo en el que se analizó la problemática dentro de la administración y se participó directamente en los trabajos en dicha área.

Fuentes secundarias. En etapa se realizó recopilación, clasificación, lectura, análisis de antecedentes bibliográficos y visitas a páginas web, lo que permitió definir un marco teórico sobre el tema, considerando una conceptualización básica, así como el conocimiento del marco geográfico, económico y social del área de estudio. Se consultaron autores como: Arriaga y Ortega (1998), Breceda (1992), Reygadas (20 I0), Bringas y Ojeda (2000), Ibáñez (2007; 20 I I), Cariño y 
Monteforte (2008), entre otros.Asimismo se examinaron documentos oficiales de instituciones de gobierno como planes de manejo, reglas de operación de programas implementados en ANP, sobre desarrollo y estrategias en materia turística y de conservación en México.

Análisis FODA. La información obtenida mediante las fuentes mencionadas fue utilizada para realizar un análisis FODA del sistema turístico del sitio. La matriz FODA O SWOT (por sus siglas en inglés) es una herramienta que sirve para ordenar los factores internos y externos que influyen en un caso de estudio. Esta técnica fue diseñada por Albert Humphrey en Estados Unidos, alrededor de los años sesenta, durante una investigación del Instituto de Investigaciones de Stanford (IIS), con el objetivo de descubrir por qué fallaba la planificación corporativa (IPN, 2002). Es considerada una herramienta útil para estructurar estrategias que disminuyan las amenazas aprovechando las oportunidades y superando las debilidades al utilizar las fortalezas. Con ello, se facilita la realización de acciones de planificación y organización de la actividad turística en forma más asertiva (Fasio, 20l0; lbáñez, 2007).

\section{Descripción del área de estudio}

San Dionisio se encuentra dentro del municipio de Los Cabos, en las coordenadas geográficas $23^{\circ} 32^{\prime} 56^{\prime \prime}$ al norte y $109^{\circ} 49^{\prime} 48^{\prime \prime}$ al oeste (véase figura I).

Es una localidad, conformada por un grupo de ranchos, que también forma parte de una ANP decretada con la categoría de Reserva de la Biosfera, conocida como Sierra La Laguna o Rebisla; además, cuenta con una importante biodiversidad reconocida internacionalmente por la Organización de las Naciones Unidas para la Educación, la Ciencia y la Cultura (Unesco), y forma parte de la red mundial de áreas con los principales tipos de ecosistemas y paisajes del planeta, destinados a la conservación (Conanp, 2003).

\section{Caracterización ambiental}

El clima de San Dionisio es semiseco, pues se ubica en la vertiente del golfo de California (Arriaga y Ortega, 1988). La ocurrencia de lluvias es más frecuente en verano, mientras que los inviernos son frescos, la precipitación media anual 
Problemática del mercado ecoturístico en la

Reserva de la Biosfera Sierra La Laguna:

El caso de San Dionisio

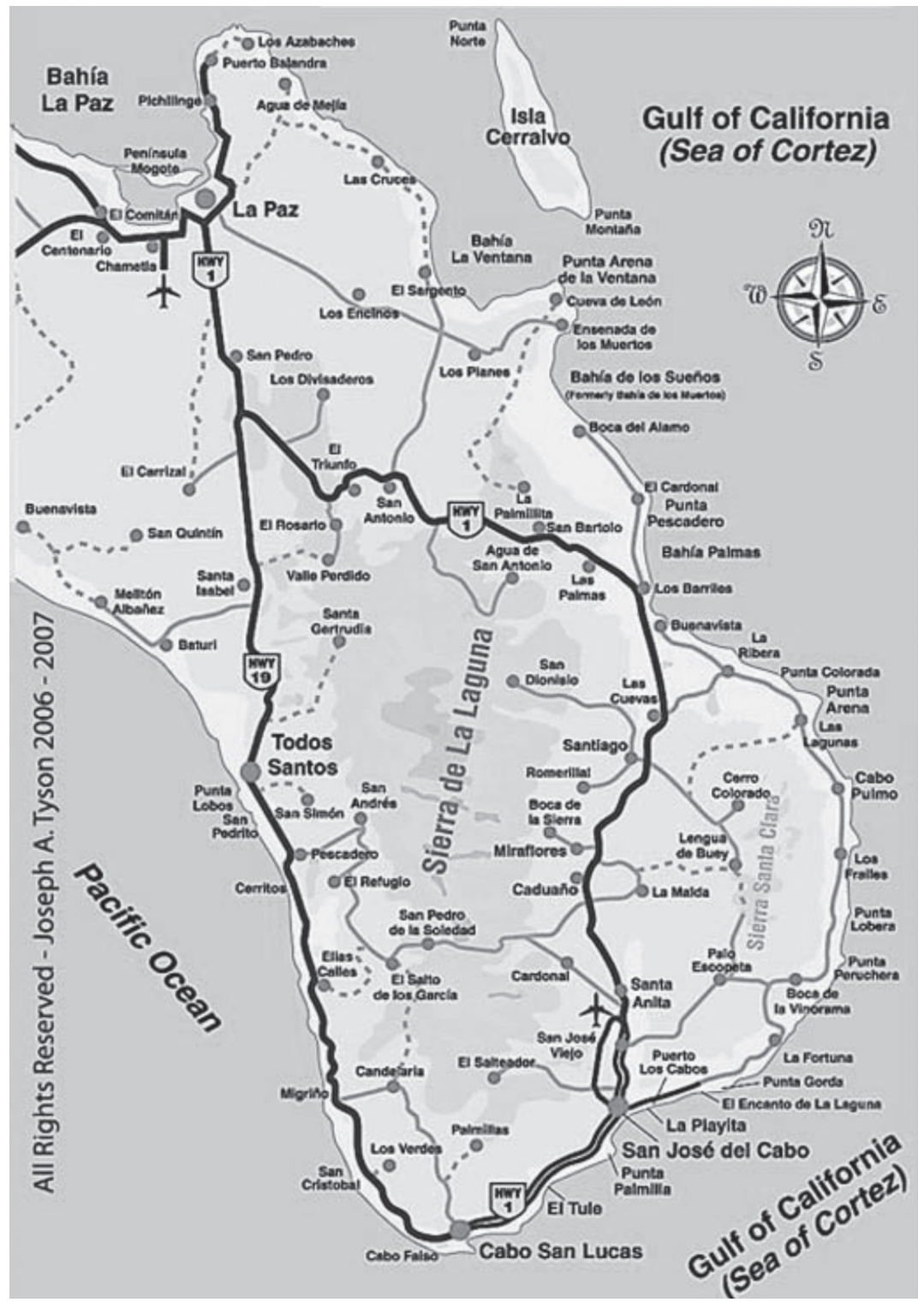

Fuente: Instituto Nacional de Estadística y Geografía (INEGI, 20I I).

figura I. Mapa de SAN Dionisio 
fluctúa entre los 300 y $500 \mathrm{~mm}$ y se registra una temperatura promedio anual de $22.7^{\circ} \mathrm{C}$.

Además, en la zona podemos observar diferentes ecosistemas; por un lado, el matorral xerófilo de vegetación sarcocaule y sarcocracicaule, con especies como mezquite, palo verde, cardón, palo fierro y gobernadora, entre otras. La parte más representativa es la de selva baja caducifolia, caracterizada por la presencia de árboles de baja talla como el torote, lomboy, ciruelo, zalate (Reygadas y Velázquez, 1983) entre otros, tal como se observa en la figura 2.
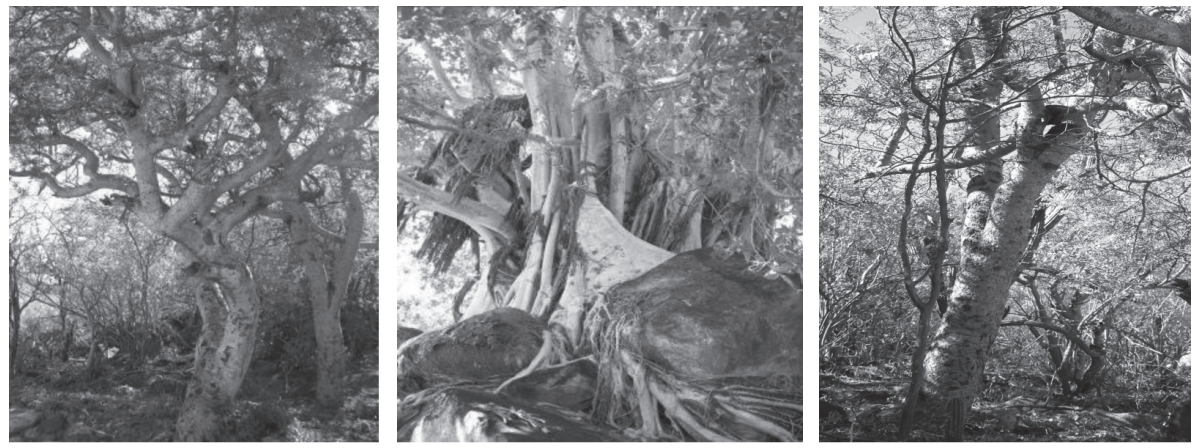

Fuente: material propio

\section{Figura 2. Flora representativa en San Dionisio}

Por otra parte, se puede observar vegetación representativa de bosque de galería al fondo del cañón y a lo largo del arroyo San Dionisio, representado por especies como palma real, palo de arco y carrizo, entre otras.Además, algunas zonas abarcan partes altas de la sierra, donde la vegetación representativa se caracteriza por ser bosque de pino-encino, es un bosque mixto compuesto por dos estratos arbóreos, uno lo representan árboles como el pino piñonero y el encino negro y el otro árboles como el madroño y el sotol, su follaje es de tipo perennifolio, es decir, siempre está verde, y se distribuye geográficamente hasta los puntos más altos (Conanp, 2003).

Es importante señalar que en la localidad estudiada se ubica un área denominada el Cañón de San Dionisio, que a su vez pertenece a una de las microcuencas hidrológicas que se presentan en La Sierra de la Laguna,y que es una de las más importantes de la región, ya que, de acuerdo con la Comisión Nacional del Agua (Conagua), abastece a ciudades cercanas como San José del 
Cabo y Cabo San Lucas, lugares en donde existe una enorme demanda del recurso agua, ya sea con fines de usos doméstico o turístico. Esto, además de una enorme riqueza natural, hace de esta zona un lugar importante por su valor ecológico y económico.

\section{Caracterización socioeconómica}

Con base en los resultados de encuestas aplicadas en la zona de estudio, se detectó que en San Dionisio están establecidos 14 ranchos, donde viven 59 personas ( 32 hombres y 22 mujeres); $45 \%$ son niños y jóvenes ubicados en un rango de edad entre los 0 a 30 años.

La mayoría de los lugareños cuenta con uno o dos cuartos construidos de material (cemento, varilla, ladrillo o block), por lo general son los cuartos donde duermen. Sin embargo, todos tienen al menos uno construido con paredes de palo de arco trabado y con base de piedra acomodada o block, el piso de tierra y el techado de palma; habitualmente ese cuarto es usado como cocina/ comedor.Además, la mayor parte de la población cuenta con seguro popular, gracias a la existencia de un centro de salud ubicado en la población de Santiago (subdelegación municipal más cercana), que sólo opera de lunes a viernes con un límite de horario hasta las tres de la tarde, por lo cual, en la ausencia del médico y enfermeros, o en casos de suma urgencia, se ven en la necesidad de demandar atención médica en localidades más distantes.

Los jóvenes y niños reciben educación preescolar, primaria, secundaria y preparatoria en el albergue escolar dependiente de la Secretaría de Educación Pública (SEP) ubicado en la población de Santiago, la mayoría de ellos permanece en el albergue durante la semana y regresan los fines de semana en un transporte colectivo, sólo unos pocos regresan diario a sus casas y lo hacen por medio de transporte propio. Es importante señalar que $24 \%$ de la población total es analfabeta, $41 \%$ ha cursado estudios de primaria, II \% cuenta con estudios a nivel secundaria, $20 \%$ cursa estudios de preparatoria y sólo $4 \%$ está estudiando el nivel superior.

Sobre el acceso a servicios básicos desafortunadamente aún se observa una enorme carencia, dado que en el área no se cuenta con electricidad por servicio público, sino que los pobladores disponen de una o dos celdas fotovoltaicas (plantas de energía solar) por rancho. 
Para abastecerse de agua, los habitantes utilizan el líquido de las cañadas conduciéndolo por gravedad a través de mangueras hasta sus hogares. Cabe destacar que, en esta región, la mayoría de la población bebe del agua obtenida directamente de las cañadas y sólo 24 \% de la población utiliza un sistema de desinfección a base de rayos ultravioleta que elimina las bacterias.

Finalmente, en cuanto a la estructura de la economía local se encontró que las actividades del sector primario que se realizan en la comunidad son: agricultura, fruticultura, apicultura; actividades pecuarias, forestales y la producción de planta en un vivero comunitario. En el sector secundario, por su parte, destaca la elaboración de dulces regionales con fruta cosechada en la región, la elaboración de chorizo, queso y artesanías (sobre todo la talabartería) y el aprovechamiento de madera para muebles rústicos. Del sector terciario sobresalen actividades turísticas de bajo impacto y servicios de alojamiento; actualmente se cuenta con dos cabañas, zonas de campamento y renta de tiendas de campaña, de bicicletas y de palapas con asadores. Se ofrece también el servicio de restaurante regional, visitas guiadas, temazcal y tirolesa (véase figura 3).
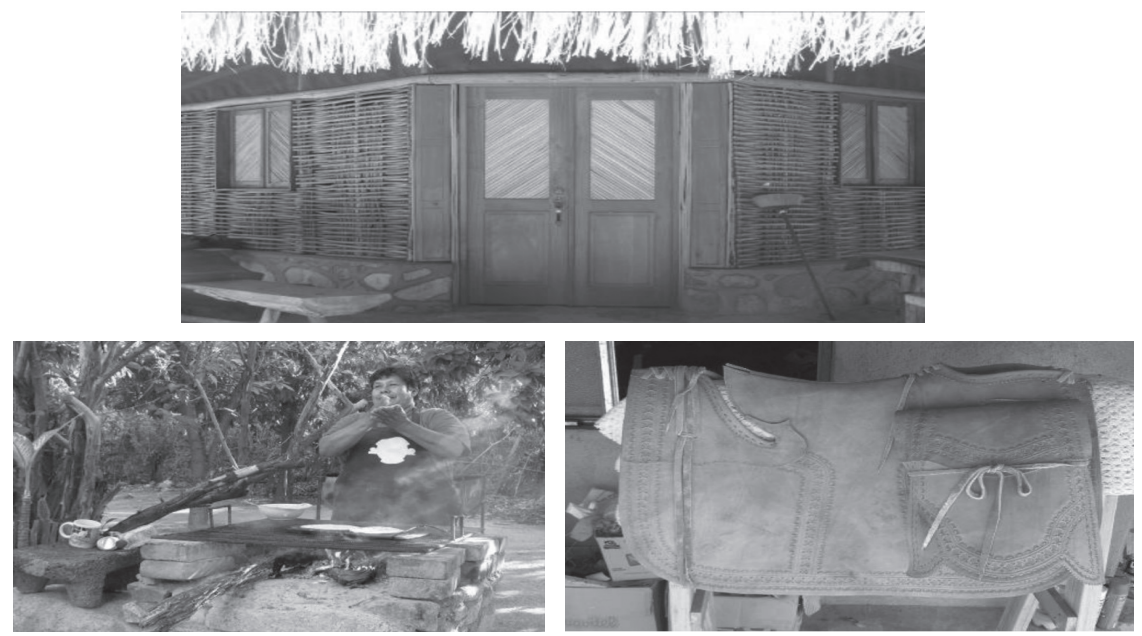

Fuente: fotografías de las autoras (2010).

Figura 3. Atractivos turísticos y forma de Vida en San Dionisio 


\section{Estructura del mercado ecoturístico en San Dionisio}

Para describir la estructura ecoturística se mencionarán los aspectos más relevantes de cada uno de los servicios ofertados en la comunidad y las características básicas de los prestadores de servicios.

\section{Servicios e infraestructura turística}

- Cabañas LaAcacia. En el rancho LaAcacia existen dos cabañas que ofrecen alojamiento a turistas, una de ellas tiene capacidad para cuatro personas. En la actualidad, el costo de renta por un grupo de cuatro personas es de 800 pesos. La segunda es más amplia, pues puede albergar ocho personas y su costo es de I 200 pesos por grupo.

- Zonas de campamento. En el rancho El Refugio se ofrece este servicio a 70 pesos por persona. El rancho El Aserradero cuenta con tres palapas, asadores y regaderas, el cobro es de 600 pesos por grupos de ocho personas. Por otro lado, en el rancho Encino Gordo se rentan tiendas de campaña a 100 pesos por tienda.

- Restaurante El Rancho. Es un establecimiento de comida regional, atendido por una familia completa, que se encarga de la elaboración de la comida utilizando tanto sus propias cosechas y productos elaborados como productos adquiridos en la localidad de Santiago. ${ }^{2}$

- Senderismo. Los lugareños conocen la flora de la región y sus usos, así como la fauna representativa. Dos personas de la comunidad ofrecen recorridos por senderos a las pozas de agua, sin planeación previa, sin objetivos claros para los recorridos, ni tarifas definidas.

- Ciclismo de montaña. Es una actividad que un habitante de la región ofrece para hacer recorridos por veredas alrededor del cañón; cobra 50 pesos por hora por persona. Para ofertar el servicio se cuenta con I 3 bicicletas con sus respectivos cascos, bombas de aire, guantes, así como cámaras de llanta, pedales, rines extra y herramienta necesaria para el correcto funcionamiento de las bicicletas.

${ }^{2}$ Es importante mencionar que dentro del rancho El Choyal se está acondicionando un establecimiento que también ofrecerá el servicio de alimentación basada en platillos típicos regionales. 
- Rancho El Guayparín. En este rancho se producen artesanías propias de la cultura ranchera sudcaliforniana, que se basan propiamente en la creación de sillas de montar, las cuales se venden a los visitantes y vecinos de las rancherías aledañas. Los precios varían, según la dedicación y detalle de las mismas (hay piezas valuadas en 20000 pesos).

- Rancho EIViejo Chinal. En este rancho se elaboran principalmente muebles de madera regional, actividad que se ha practicado por generaciones. También, se elaboran otras artesanías que son vendidas fuera de la localidad, casi siempre a extranjeros. Los precios son variables según los diseños y el material de las piezas, por ejemplo, una silla elaborada de palo chino y piel se vende en alrededor de 700 pesos.

- Temazcal. Este servicio se oferta en el rancho El Refugio, donde existe una estructura de palo de arco, en forma de bóveda, que durante la visita del turista se cubre con cobijas. El precio por persona incluyendo la comida es de 300 pesos.

- Visitas guiadas. El área boscosa de La Sierra de la Laguna, así como sus cascadas y el picacho, son lugares frecuentemente visitados por estudiantes y turistas en general. Por ello, uno de los habitantes de los primeros ranchos de la comunidad (Las Veredas), oferta servicios de visitas guiadas. Si bien oficialmente no cobra una tarifa, usualmente recibe el pago que los turistas deseen otorgarle. Otra persona que presta este servicio radica en uno de los últimos ranchos (Encino Gordo); a diferencia del anterior, ella sí tiene una tarifa definida, de 2000 pesos por grupo.Asimismo, en el rancho El Refugio se ofrecen visitas guiadas por un costo de 400 pesos por día por persona, incluyendo la bestia de montar.

- Tirolesa. Esta actividad está por inaugurarse,y aún no se ha establecido una tarifa.

- Renta de bestias. Una familia oferta el servicio de renta de mulas a los visitantes que suben a La Sierra; las rentan especialmente para carga, a un costo de 400 pesos por día. 
Perfil de los prestadores de servicios

La mayoría de los prestadores de servicios turísticos son nativos de la localidad, con estudios máximos de primaria y con un enorme conocimiento de la flora y fauna del lugar, cuentan con conocimientos básicos de primeros auxilios y tienen amplio conocimiento de las tradiciones y leyendas populares. Les caracteriza su honestidad y excelente trato a los visitantes, independientemente de la nacionalidad de éstos.

Existen por lo menos diez prestadores de servicios turísticos externos, operando con permiso federal dentro del área de La Sierra de la Laguna; sólo dos de ellos operan específicamente en San Dionisio.

Con respecto a los servicios ofertados por los prestadores de servicios (tanto locales como externos) se incluyen actividades como caminatas, observación de flora y fauna, campismo, actividades recreativas y educación ambiental.

Sobre el perfil del turista

Como se observa en la gráfica I, la mayor parte la conforman personas entre 5 I-60, 4I-50 y 30-40 años de edad, ya que dentro de esos rangos se ubicaron 45 de los 59 turistas encuestados.

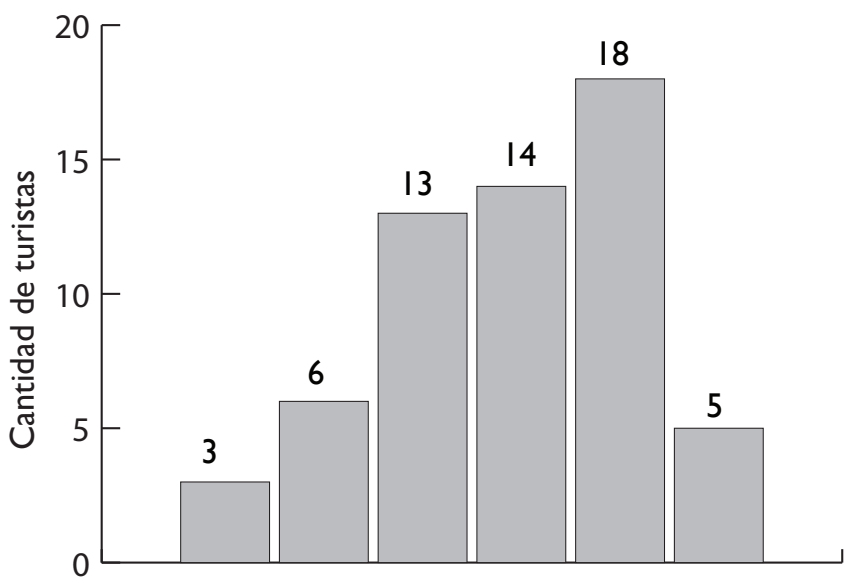

Gráfica I. Rango de edades de turistas de San Dionisio 
- Procedencia . De acuerdo con las encuestas, $61 \%$ de los turistas son nacionales y $39 \%$ extranjeros. A su vez, $97 \%$ de los turistas nacionales son originarios del estado de B.C.S., de los cuales $63 \%$ radica en el municipio de Los Cabos y 37 \% en el de La Paz.

- Estancia. 56 \% de los turistas visitan la zona por un día, 36 \% permanece dos días, es decir, al menos una noche, y sólo 8 \% (equivalente a cinco turistas) permanece por tres días o más.

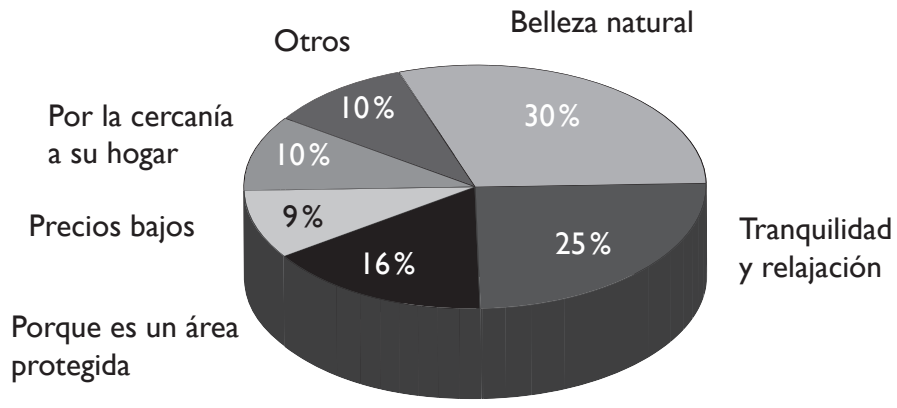

Fuente: Elaboración propia con base en encuestas aplicadas, 2010.

Gráfica 2. Motivo de viaje del turista de San Dionisio

- El motivo del viaje. Como se observa en la gráfica 2, por lo menos 18 turistas, es decir $30 \%$ del total encuestado, prefiere visitar el área por su belleza natural, Asimismo, la recomendación de persona a persona representó el principal medio para enterarse de la existencia del lugar.

- Índice de satisfacción del cliente. Este índice considera la percepción sobre las comodidades del área y el nivel con que se califica la calidad de los servicios. Según datos de las encuestas, los turistas manifiestan un índice alto de satisfacción del producto, ya que ninguno de ellos se manifestó inconforme, lo cual es una gran ventaja.

- Expectativas del cliente. Para conocer las expectativas del cliente se cuestionó a los turistas sobre su predilección por actividades vinculadas 
a segmentos específicos y modalidades del turismo. Los resultados de las encuestas muestran una preferencia hacia las actividades de turismo alternativo. Las de mayor inclinación según la oferta actual en San Dionisio son las correspondientes al turismo de aventura. Sin embargo, al preguntar sobre sus expectativas, $52 \%$ de los encuestados (3I turistas) se manifestó por el desarrollo de actividades vinculadas al ecoturismo, $29 \%$ ( 17 turistas) mostró preferencia por actividades relacionadas con el turismo de aventura, y sólo $19 \%$ se inclinó por el turismo rural.

\section{Resultados del análisis FODA de la actividad turística en San Dionisio}

Una vez analizados los aspectos que favorecen y desfavorecen el buen desarrollo del turismo en la zona de estudio los agrupamos, según su naturaleza, en fortalezas, oportunidades, debilidades y amenazas, tal como se aprecia en el cuadro I.

\section{Fortalezas}

Se refieren a características que representan ventajas para alcanzar los objetivos o posiciones favorables y que pueden colocar a la localidad en condiciones de responder eficazmente ante una oportunidad o una amenaza. En el caso de San Dionisio, algunas de las principales fortalezas detectadas son:

Cercanía al municipio de Los Cabos. En términos estadísticos, Los Cabos concentra cerca del $86 \%$ de la oferta de servicios turísticos del estado de BCS y forma parte de uno de los destinos turísticos más conocidos del país. Una ventaja para la comunidad de San Dionisio, por su cercanía a ese polo de desarrollo, es la posibilidad de acceder a ese mercado, cubriendo diferentes necesidades del visitante, ofertando productos innovadores que complementen la marcada estacionalidad del turismo de Los Cabos.

Actitud consciente del valor ambiental. Los lugareños conocen su tierra y la valoran mejor que otras personas. Están conscientes de los beneficios que la naturaleza les brinda y saben que lo más importante del decreto como área protegida es "conservar". Prueba de ello es que la mayoría participa en mayor o menor medida en la conservación del sitio. 


\section{Fortalezas}

A) Ambiental

- Cercanía al municipio de Los Cabos

- Actitud consciente del valor ambiental

- El clima agradable

- Utilización de biotecnología

- Enorme biodiversidad y atractivos naturales

B) ECONÓMICO Y CULTURAL

- Satisfacción de los turistas que visitan la comunidad

- Comunidad hospitalaria y pacífica

- Prestadores de servicios turísticos nativos

- Riqueza histórico-cultural

- Cultura propia de un ranchero sudcaliforniano

- Sitio decretado por la Unesco como patrimonio de la humanidad

C) Marco legal y gobierno

- Participación local en el Decreto como ANP

- Cuenta con un Programa de Conservación y Manejo (PCyM) de la Rebisla

\section{Debilidades}

A) Ambiental

- Ausencia de estudios de capacidad de carga turística local

- No se cuenta con inventarios de flora y fauna

B) ECONómico Y CULTURAL

- Insuficiente organización y comunicación comunitaria

- Insuficiente señalización

- Deficiente infraestructura sanitaria

- Escasa publicidad

- Necesidad de capacitación en temas relacionados con calidad y servicio al cliente

- Desconocimiento de la variedad de fuentes de financiamiento

- Falta de responsabilidad con respecto a los apoyos recibidos

- Riesgo de emigración de la población local por falta de visión turística

- Abandono de las tradiciones locales, como resultado de cambios en las actitudes de los jóvenes locales

C) Marco legal y gobierno

- Escaso seguimiento y vigilancia de proyectos locales

- Carencia de criterios legales claros para el otorgamiento de apoyos económicos

continúa

Fuente: Elaboración propia con base en encuestas aplicadas en 2008 y 2010. 
Problemática del mercado ecoturístico en la

Reserva de la Biosfera Sierra La Laguna:

El caso de San Dionisio

Cuadro I.Análisis foda del ecoturismo en la comunidad de San Dionisio

(finaliza)

\section{Oportunidades}

A) AMBiENTAL

- Oportunidad de aprovechar sustentablemente su riqueza natural

- Interés de organizaciones internacionales por conservar zonas con alta biodiversidad

- Posibilidades de certificación ambiental en algunos segmentos del turismo

B) ECONÓMICO Y CULTURAL

- Posibilidad de diversificar las fuentes de empleo al participar en los programas de empleo temporal (PET) ofrecidos por la Conanp

- Posibilidad de obtener subsidios para diversificar las actividades productivas a través del Programa de Conservación y Desarrollo Sostenible

- Potencial para absorber segmentos de mercado muy especializados

- Posibilidad de canalizar algunos arribos de turistas

- Opciones de superación educacional al existir programas de educación a nivel medio y superior enfocados hacia el turismo alternativo

- Posibilidades de profesionalización turística gracias a la existencia de esquemas de certificación profesional

C) Marco legal y gobierno

- Plan Nacional de Desarrollo

- Programa Sectorial de Turismo, Programa Nacional de Turismo en ANP

- Estrategia nacional de turismo en ANP

- Leyes y programas nacionales y estatales que propician el desarrollo rural
A) Ambiental

- Fenómenos meteorológicos

- Falta de conciencia ambiental por parte de algunos visitantes de la zona

- La incapacidad en el manejo de turistas tiende a elevar sus impactos ambientales

- Incumplimiento de la normatividad ambiental

B) ECONómico Y CULTURAL

- Recesión económica mundial

- Riesgo de saturación de la oferta turística

- Riesgo de pérdida de identidad, al igual que en otros destinos turísticos

- Tendencia a incremento de precios debido al aumento y creación de nuevos impuestos

C) Marco legal y gobierno

- Excesiva burocracia para la implementación de nuevas empresas

- Falta de un marco legal y normativo actualizado y acorde a la realidad en la que viven localidades rurales 
Clima agradable. El clima generalmente es fresco, lo cual favorece la práctica de actividades al aire libre, y se convierte en un atractivo para conquistar visitantes extranjeros.

Utilización de biotecnología. Los lugareños han aprendido a transformar y manipular lo que les ofrece la naturaleza de manera natural y en función de sus necesidades, tal es el caso de la transformación de los alimentos.

Satisfacción de los turistas que visitan la comunidad. Las encuestas realizadas a los visitantes de la localidad han demostrado que expresan un alto índice de satisfacción en la percepción del producto obtenido. Esto nos dice que, hasta la actualidad, los prestadores de servicios turísticos han satisfecho las expectativas de los visitantes en cuanto a la calidad del servicio directo que les proporcionan. Comunidad hospitalaria y pacífica. Esta fortaleza es muy importante, ya que es una de las razones por las que el turista regresa al lugar. Por fortuna, los lugareños son personas que reciben a sus visitantes de manera amable y se presume ser un lugar sumamente tranquilo, por lo que los visitantes demuestran su preferencia por la zona.

Prestadores de servicios turísticos nativos. Como la comunidad conoce y respeta el lugar no se necesita mucha capacitación para el uso de tecnología, los pobladores se guían más por sus conocimientos heredados tradicionalmente, que por la tecnología.

Cultura propia de un ranchero sudcaliforniano. Afortunadamente, en San Dionisio no se han perdido muchas de las antiguas tradiciones y por ello se considera un lugar privilegiado. Como ejemplo de estas tradiciones podemos mencionar la talabartería, la doctrina, la elaboración de vino y azúcar de caña, entre otras actividades.

Decreto como ANP. El hecho de que se haya decretado como ANP le permite contar con mayor acceso a fondos para la realización de actividades sustentables.

Programa de Conservación y Manejo (PCyM) de la Rebisla. Este documento establece lineamientos generales para el desarrollo y zonificación de las actividades económicas, y resalta la importancia histórico-cultural, ecológicacientífica, y educativa-recreativa del área. 


\section{Oportunidades}

Se consideran una oportunidad todos los factores que resultan favorables o explotables, y que se deben descubrir en el entorno en el que se estudia. También son oportunidades las situaciones, recursos o características externas que se pueden aprovechar. En este caso, algunas de las oportunidades son:

Oportunidad de aprovechar sustentablemente su riqueza natural. En la actualidad existe una tendencia a realizar y fomentar actividades y actitudes acordes con el cuidado del ambiente.

Interés de organizaciones internacionales por conservar zonas con alta biodiversidad. Se refleja en la firma de acuerdos y compromisos internacionales vinculados con la implementación de mecanismos de cooperación en materia ambiental.

Posibilidades de certificación ambiental, en algunos segmentos del turismo. Actualmente se busca certificar actividades consideradas amigables con el medio ambiente, tal es el caso del ecoturismo.

Participar en los programas de empleo temporal (PET) de la Conanp. El PET ofrece a los habitantes de las ANP empleos para el mejoramiento, protección, rehabilitación de territorios privados, ejidales, comunales o nacionales, generando, de manera implícita, una alternativa de ingresos económicos a sus hogares.

Obtener subsidios del Programa de Conservación y Desarrollo Sostenible (Procodes). El Procodes es un programa que ofrece financiamiento a los habitantes que desean emprender una microempresa o que requieren de capacitación para algún oficio.Todo ello, encaminado a la conservación de los recursos naturales.

Potencial para absorber segmentos de mercado muy especializados. Propiamente, es un área potencial para aprovechar sus recursos naturales y ofrecer actividades como avistamiento de flora y fauna, observación geológica, observación de ecosistemas, entre otras. De esta manera, su riqueza constituye una oportunidad para entrar en este tipo de mercado.

Existencia de planes, programas y estrategias nacionales vinculados con la actividad turística. Por mencionar algunos: el Plan Nacional de Desarrollo 2007-20 I2, el Programa Sectorial de Turismo 2007-20 I2, el Programa Nacional de Turismo en ANP, la estrategia nacional de turismo en ANP, así como diversas leyes que propician el desarrollo del turismo en zonas rurales; o bien que señalan esta actividad como pieza clave para el desarrollo del país. 


\section{Debilidades}

Las debilidades son factores que provocan una posición desfavorable frente a los retos del desarrollo. Son obstáculos o la carencia de recursos o habilidades que impiden la realización adecuada de las actividades económicas. Entre las principales debilidades detectadas se encuentran:

No existen estimaciones de la capacidad de carga turística de la localidad. No se ha determinado un límite de visitantes por área, y en ocasiones se reciben demasiadas personas en un mismo espacio.

No existen inventarios de flora y fauna. Aunque los rancheros tienen conocimiento pleno del lugar donde habitan, el hecho de no contar con una guía o inventario de la flora y fauna que los rodea se vuelve una debilidad, dado que esto dificulta labores de educación ambiental.

Organización y comunicación comunitaria nula. Ésta es una debilidad muy evidente de la comunidad, pues pese a sus lazos familiares no se apoyan de la forma necesaria para progresar conjuntamente.

Falta de señalización. A lo largo del camino de la comunidad, no se cuenta con suficientes letreros que atraigan la atención de los visitantes y que los ayuden a encontrar lo que buscan.

Falta de publicidad. Gran parte de los lugareños admite que no cuenta con ningún sistema de publicidad (escrita o página de Internet) para información y reservaciones.

Necesidad de capacitación en temas relacionados con calidad y servicio al cliente. Desde que comenzó la gestión turística en la localidad, no se han impartido cursos de capacitación en temas relacionados con la calidad en el servicio al cliente.

Desconocimiento de la variedad de fuentes de financiamiento. La falta de información sobre posibles fuentes de financiamiento representa uno de los principales factores que limitan la realización de proyectos y la modernización de las empresas existentes.

Riesgo de emigración de la población local por falta de visión turística. La emigración en poblaciones rurales se debe a la falta de oportunidades para obtener buena 
calidad de vida. En San Dionisio existen condiciones para realizar actividades productivas diversas, sin embargo, es necesario que se capacite a sus habitantes para que sean capaces de aprovechar tal potencial. Con ello, se genera más apego al sitio y se proporcionan mayores opciones para mejorar el nivel de vida de la localidad.

Abandono de las tradiciones locales, como resultado de cambios en las actitudes de los jóvenes locales. Existe una fuerte tendencia a que los jóvenes de San Dionisio se trasladen a la ciudad (ya sea en busca de mejores oportunidades o bien con fines de superación educativa) y, derivado de la interacciones que establecen con la población citadina, los jóvenes rancheros adoptan costumbres, valores y actitudes predominantes en las grandes ciudades, con lo que, al paso de los años, se hace cada vez más difícil preservar las raíces de la cultura local.

Escaso seguimiento y vigilancia de proyectos locales. Son pocos los proyectos impulsados por el sector gobierno que hayan sido objeto de seguimiento y evaluación de resultados. Esto representa una debilidad importante, pues muchas veces la falta de apoyo ( $y$ en ausencia de capacitación especializada, principalmente en cuestiones técnicas) lleva a que muchos de los proyectos o negocios cierren.

\section{Amenazas}

Las amenazas son situaciones desfavorables, actuales o futuras, y externas, que representan desventajas y sobre las cuales no se tiene control directo. Para San Dionisio, las principales amenazas detectadas son:

Fenómenos meteorológicos. Sin duda, los fenómenos meteorológicos, como los huracanes, son un fuerte impedimento para realizar actividades al aire libre; de igual manera, la alta insolación en verano es un factor muy peligroso para la gente. Por esta razón se consideran amenazas externas que no se pueden controlar.

Falta de conciencia ambiental por parte de algunos visitantes de la zona. En la actualidad, este problema no se presenta con mucha frecuencia; sin embargo, sigue siendo una preocupante amenaza potencial.

Recesión económica mundial. El turismo es uno de los más afectados por la 
crisis económica. Por ende San Dionisio, al ser una comunidad rural con bajos ingresos, indudablemente se ve afectada.

Riesgo de saturación de la oferta turística. Si no se tiene idea de los patrones de demanda puede propiciarse, como en cualquier otro destino turístico, la sobreoferta de servicios.

Riesgo de pérdida de identidad. Este riesgo se agudiza en localidades que interactúan con personas de diferente nacionalidad. Por tal motivo, la actividad turística puede constituir un arma de doble filo: por un lado puede elevar los ingresos, pero por otro puede contribuir a la pérdida de costumbres y valores.

Excesiva burocracia para la implementación de nuevas empresas. Esto inhibe la creación de nuevas unidades económicas en zonas rurales, ya que los emprendedores de las empresas tienen que viajar a la ciudad para realizar diversos trámites, lo que demerita su bolsillo y los obliga a dejar en el abandono sus ranchos y propiedades.

Mediante el diagnóstico anterior se aportan elementos para formular medidas precisas que mejoren el desarrollo del ecoturismo en la localidad, siempre y cuando las estrategias implementadas busquen superar las debilidades, aprovechar las oportunidades y disminuir lo máximo posible las amenazas al usar adecuadamente las fortalezas existentes.

\section{Discusión y conclusiones}

La problemática en la comunidad estudiada no sólo alude a la planeación, sino también a la organización, implementación y seguimiento de los procesos de desarrollo local.

Pese a que desde 2004 los proyectos turísticos puestos en marcha han sido en su mayoría apoyados por subsidios provenientes de la Conanp, y que cumplieron con los objetivos y las reglas de operación de esa institución, al hacer énfasis en la preservación del medio ambiente, los criterios de selección para tales proyectos son austeros en materia de turismo, pues para ser aceptados se consideran aspectos muy generales, que en algunos casos no corresponden a la zona. Lo más grave es que aún no se han implementado mecanismos claros para dar seguimiento a estos proyectos. Además, existe una fuerte desarticulación 
en las acciones encaminadas al desarrollo turístico dentro del área, lo que exige mayor transversalidad y coherencia en las estrategias turísticas, pues hoy en día se plantea impulsar el turismo como una actividad económica acorde con la conservación de estas ANP y se hace indispensable adoptar estrategias para no poner en riesgo su sustentabilidad.

Por otro lado, si bien es cierto que la localidad estudiada posee un valor cultural singular, propio de la vida ranchera sudcaliforniana, casi la mitad de los habitantes actuales son jóvenes y muchos de ellos están desistiendo de los hábitos de esta cultura, puesto que conviven y aprenden de la cultura urbana y se envuelven en ella dejando de lado sus costumbres y tradiciones.

Asimismo, aunque San Dionisio es un lugar visitado por su belleza escénica natural y por la tranquilidad y relajación que produce estar en contacto con el medio natural, su oferta turística hasta hoy se ha sustentado en los productos propios del turismo de aventura. Sin embargo, esto no representa necesariamente una desventaja, ya que al analizar la oferta según las tres modalidades del turismo alternativo éstas se encuentran estrechamente ligadas y bien proporcionadas entre el total de la oferta local.

El principal problema dentro del mercado ecoturístico de la localidad es la carencia de planeación estratégica para ofrecer y publicitar las actividades de ecoturismo y turismo rural, pues son las que menos se aprovechan en la zona a pesar de su alto potencial y el progresivo interés de los visitantes por practicarlas.

Finalmente, dado que el sistema ecoturístico en San Dionisio está vinculado directamente a un área protegida, tiene más oportunidades de desarrollarse de manera sustentable, dado que se garantiza la participación de la comunidad en el turismo y se establecen lineamientos ambientales para realizar todo tipo de actividades. Esto no ocurre en los sitios que no están decretados bajo ninguna categoría de protección: ahí las actividades son practicadas libremente y en muchos casos por extranjeros que compran las tierras a ejidatarios, de manera que no se garantiza que los beneficios del desarrollo turístico sean para las comunidades receptoras, además de que se pone en riesgo la sustentabilidad local. 


\section{Recomendaciones y consideraciones finales}

A las microempresas ya establecidas

- Para ser competitivos en una industria tan cambiante como el turismo, es necesario que los prestadores de servicios en esta área se capaciten con cursos sobre atención y servicio al cliente.

- Se requiere llevar a cabo un registro de visitantes para construir una base de datos que permita a las empresas conocer su nicho de mercado y las necesidades de sus clientes para así elaborar estrategias basadas en datos que las lleven al éxito.

- Se recomienda que los negocios más afianzados (Cabañas La Acacia) busquen la certificación de la Norma Oficial Mexicana Voluntaria de Ecoturismo (NMX-I33), puesto que para los visitantes sería una garantía de que se les ofrecen actividades con un mínimo impacto ambiental y que cubren los tiempos de ocio generados durante su estancia en el lugar.

- Se sugiere buscar la certificación de la Secretaría de Salud (ss) en conjunto con la Sectur y de esta manera tener una mayor ventaja y contar con la plena confianza en el cliente.

- Es necesario que las empresas apliquen individualmente métodos para medir la satisfacción del cliente.

- Es recomendable que los comunitarios aprovechen el potencial para practicar el turismo de observación sideral, que actualmente no se está ofreciendo pero que es una oportunidad con la cual cubrir tiempo de ocio por las noches.

- Es fundamental manejar paquetes, promociones y descuentos para atraer a los visitantes, ya que son microempresas poco conocidas.

- Es imperioso que los lugareños eduquen a las generaciones jóvenes transmitiéndoles conocimientos ancestrales como legado propio y herencia de habilidades que los distinguen y que aprovechándolos pueden convertirse en fuente de ingresos económicos. 
A las autoridades responsables de la administración del ANP

- Elaborar folletos actualizados de San Dionisio y distribuirlos en lugares estratégicos.

- Gestionar ante la Secretaría de Comunicaciones y Transportes (SCT) la posición de un letrero sobre la carretera federal, donde parte la entrada a la localidad de Santiago (cabecera delegacional de la localidad), pues de esta manera es más fácil saber del sitio mediante información de la Rebisla.

- Dado que gran parte de la población está conformada por niños y jóvenes, los cuales han recibido poca o nula capacitación en temas de educación ambiental y turismo, es necesario considerarlos en mayor medida ya que son el futuro del desarrollo de la comunidad. Ellos serán el presente en unos años y de su visión sobre el lugar donde residen dependerá en gran parte el rumbo que tenga el sitio como turístico.

- Incentivar la apertura de empresas con actividades que forman una identidad propia de la vida del ranchero sudcaliforniano, que, como lo señala el Plan Nacional de Desarrollo (PND) para el turismo en ANP, no degraden su cultura y que generen una identidad propia que los diferencie de los demás, puesto que la oferta de productos únicos en una región alienta la llegada de turistas. Además, rescatar los valores históricos y culturales de la zona es parte de los objetivos del PCyM del área.

- Se recomienda capacitar a los lugareños en trabajo comunitario para combatir la problemática tan arraigada de trabajar mediante esfuerzos individuales, ya que el turismo alternativo es básicamente el trabajo en unión para que sea efectivo. Como referencia, en la segunda línea de acciones generales del PND para el Turismo en ANP se aborda como punto importante el desarrollo de infraestructura y servicios de apoyo al turismo, señalización, senderos, centros de visitantes (centros de comunicación y cultura para la conservación, sanitarios y estacionamientos). Dentro del mismo documento, en la tercera línea de sus acciones generales se habla de promover en los visitantes una cultura conservacionista de las ANP. Por ello, se sugiere acondicionar el establecimiento donde anteriormente se efectuaba el cobro de 
derechos como un centro de cultura para la conservación, dirigido a turistas, estudiantes e investigadores que llegan a San Dionisio, con el fin de informarlos y concientizarlos sobre temas relacionados con el cuidado del medio ambiente.

- Es primordial que las autoridades encargadas de la administración del área analicen el PCyM, con una perspectiva que incluya estrategias y lineamientos precisos sobre la realización de actividades vinculadas al turismo alternativo, incluyendo criterios más restrictivos para la selección de proyectos de turismo alternativo en la zona, como puede ser: que se apoyen con orden los proyectos según la modalidad de turismo alternativo y que se busque cumplir con el fin, así puede aprovecharse la zona de los ranchos para el turismo rural, la zona de la entrada a San Dionisio y el arroyo para el turismo de aventura, y las cañadas y zonas más adentradas de la sierra para el ecoturismo.

- Se recomienda promover la diversificación de la oferta turística con ideas realistas y factibles de implementar en la localidad, así como canalizar acciones en materia de empleo temporal en la restauración de la infraestructura local (letrinas, caminos, cercos) para satisfacer las necesidades de los visitantes.

- Es menester fomentar la participación de la localidad en festivales culturales y artísticos y en exposiciones, donde se den a conocer los proyectos que han tenido éxito en la localidad, las artesanías y actividades que se realizan en la zona.

- Es indispensable promover el rescate de las tradiciones de la comunidad y la sierra en general, por ejemplo mediante reuniones de rancheros donde compartan sus experiencias y habilidades distintivas.

\section{FUENTES CONSULTADAS}

Acerenza, M. (2006). Conceptualización, origen y evolución del turismo. México: Trillas.

Arriaga, L. y A. Ortega (1988). La sierra de La Laguna de Baja California Sur. La Paz: Centro de Investigaciones Biológicas de Baja California Sur.

Breceda, A. ( 1992). La sierra de La Laguna. Fundamentos para apoyar la creación 
de una reserva de la biosfera. La Paz: Centro de Investigaciones Biológicas de Baja California Sur.

Bringas, N. y L. Ojeda (2000). "El ecoturismo: ¿una nueva modalidad del turismo de masas?” Economía, Sociedad y Territorio, II (7), 373-403. Toluca: El Colegio Mexiquense.

Cariño, M. y M. Monteforte (2008). Del saqueo a la conservación. México: Secretaría de Medio Ambiente y Recursos Naturales.

CB (1987). Nuestro futuro común, informe de la Comisión Mundial para el Medio Ambiente y el Desarrollo. Estocolmo: Comisión Mundial para el Medio Ambiente y el Desarrollo y Asamblea General, Comisión Brundtland, Desarrollo y Cooperación Internacional.

Conanp (2003). Programa de Manejo Reserva de la Biosfera Sierra La Laguna. México: Comisión Nacional de Áreas Naturales Protegidas.

(2007). Programa Nacional de Áreas Naturales Protegidas: 2007-20I 2.

México: Comisión Nacional de Áreas Naturales Protegidas.

(20II). Estrategia nacional para un desarrollo sustentable del turismo y la recreación en las áreas protegidas de México. México: Comisión Nacional de Áreas Naturales Protegidas. Disponible en: http://www. conanp.gob.mx/pdf_publicaciones/TurismoEstrategia.pdf [20II, 2 de febrero].

Fasio, L. (2010). Turismo alternativo y tendencias de desarrollo en un área natural protegida: el caso Cañón de San Dionisio, reserva de la biosfera, Sierra La Laguna. Tesis de licenciatura. La Paz: Universidad Autónoma de Baja California Sur (UABCS).

Ibáñez P., R. M. (2007). Turismo alternativo, gestión y desarrollo local: el caso de Cabo Pulmo, B. C. S. Tesis de maestría. La Paz: UABCS.

(20 I la). "Crecimiento económico, desarrollo sustentable y turismo: Una aproximación del posicionamiento de Baja California Sur (BCS) en el barómetro de la sustentabilidad". El Periplo Sustentable, 20, enero-junio, 75-I I8. Universidad Autónoma del Estado de México. (20l lb). "Competitividad y calidad de los servicios turísticos en México". Cuadernos de Turismo. Universidad de Murcia (artículo por publicarse en el núm. 28).

INEGI (20I I). Mapas de Baja California Sur. Instituto Nacional de Estadística y Geografía. Disponible en: www.inegi.org.mx [201 I, 2 de febrero]. IPN (2002). Metodología para el análisis FODA. México: Dirección de Planeación 
y Organización del Instituto Politécnico Nacional. Disponible en: http://www.uventas.com/ebooks/analisis_foda.pdf [20II, 2 de febrero].

Reygadas, F. (20I0). La historia natural y cultural de la reserva de la biosfera Sierra

La Laguna. Una perspectiva para planificar el turismo rural y el turismo de naturaleza. La Paz: UABCS.

Reygadas, F. y G. Velázquez (1983). El grupo pericú de Baja California. La Paz: Fondo Nacional para Actividades Sociales.

Sectur (2004). Turismo alternativo, una nueva forma de hacer turismo. México: Secretaría de Turismo (fascículo).

(2007). Programa Sectorial de Turismo 2007-20 I 2. México: Secretaría de Turismo.

Semarnat (2003). Introducción al ecoturismo comunitario. Centro de Educación y Capacitación para el Desarrollo Sustentable. México: Secretaría de Medio Ambiente y Recursos Naturales.

Wearing, S. y J. Neil (1999). Ecoturismo, impacto, tendencias y posibilidades. Madrid: Síntesis. 
